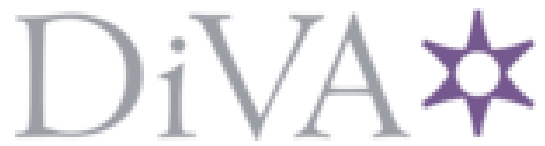

http://www.diva-portal.org

\title{
Postprint
}

This is the accepted version of a paper presented at PMAPS Conference 2018.

Citation for the original published paper:

Vieira Turnell, A., Linnet, A., Tamadon, N., Morozovska, K., Hilber, P. et al. (2018)

Risk and economic analysis of utilizing dynamic thermal rated transformer for wind farm connection

In: Milorad Papic (ed.),

N.B. When citing this work, cite the original published paper.

Permanent link to this version:

http://urn.kb.se/resolve?urn=urn:nbn:se:kth:diva-226544 


\section{Risk and economic analysis of utilizing dynamic thermal rated transformer for wind farm connection}

\author{
Alice Vieira Turnell, Agnes Linnet, Nahal Tamadon, \\ Kateryna Morozovska ${ }^{a}$, Student Member, IEEE and \\ Assoc. Prof. Patrik Hilber, Senior Member, IEEE \\ ${ }^{a}$ School of Electrical Engineering and Computer Science \\ KTH Royal Institute of technology \\ Stockholm, Sweden \\ Email: kmor@kth.se
}

\author{
Dr. Tor Laneryd \\ Corporate Research, \\ ABB AB Västerås, Sweden
}

\begin{abstract}
Dynamic transformer rating (DTR) can be used to load power transformers above nameplate rating, while respecting contingency loading limits and ensuring an acceptable risk level. Purchase of power transformers is a major contributor for high costs of building new substations. Application of DTR allows to postpone the investment in new power transformers in old substations, thus DTR has a potential to become an economically beneficial technology. A quantitative risk and economic evaluation of DTR application is performed for a wind farm connected transformer and thus for a highly variable load scenario. The risks analyzed in this project are increased loss of insulation life and the risk of dielectric failure, based on the ArrheniusWeibull model. A comparative net present value calculation has been performed to investigate the profitability of replacing a 19.4 MVA transformer with a 16 MVA dynamically rated transformer. The feasibility of DTR application is analyzed and a methodology is developed to support both transformer manufacturer and potential customers, such as distribution system operators, in the decision-making process of purchasing of dynamically rated transformer for wind energy applications.
\end{abstract}

\section{INTRODUCTION}

Power system utility companies have a need to optimize their capacity usage to provide their customers with lowest cost at an acceptable risk level. Dynamic rating is a relatively new method aimed at increasing the capacity utilization of equipment, driven by gathering and analyzing information regarding system and environmental conditions. For a wind farm connected transformer, the unpredictability of the load as well as its high variability represents an extra challenge in effectively sizing the transformer with dynamic rating. This requires thorough risk and economic assessments, in order to sustain system reliability and component life expectancy [1]. The life expectancy of transformer is affected by insulation aging and, more specifically, by hottest-spot temperature (HST). The heat balance of a transformer depends on load and ambient conditions. Thermal models are used to present the transformer HST as a function of the load and ambient temperature. The heat distribution in transformer is not uniform, therefore information on the HST is of interest, when predicting transformer thermal behavior. Commonly used thermal models are provided by IEEE and IEC standard guidelines. IEEE has two thermal models for transformers: IEEE Clause 7 and IEEE
Annex G [2]. The International Electrotechnical Commission (IEC) has also introduced two thermal models: exponential equations model and differential equations model [3]. The HST calculations in the following study are using the IEC differential equations method [3] [4].

According to the IEEE Guide for loading oil-immersed transformers [2], a transformer insulation is designed to withstand constant load for 17.12 years, provided that the hot spot temperature is $110{ }^{\circ} \mathrm{C}$ during all operation time for $65^{\circ} \mathrm{C}$ average winding rise transformers [2]. The static rating is designed to ensure that the transformer can withstand the worst-case scenario conditions. When using nameplate ratings, the equipment capacities are not fully utilized, which leads to higher investment costs. The application of DTR allows loading a transformer above nameplate rating, while respecting the limits of contingency loading [5]. Overload conditions increase the risk of faster insulation aging and the risk of failure due to increased formation of bubbles in the oil, which affects insulation and reduces capability to withstand short circuit faults [4, p. 28]. The DTR provides a possibility to optimize transformer capacity without compromising the insulation aging rate and transformer life expectancy.

\section{Methodology}

\section{A. Risk analysis}

Increased temperature in the transformer windings leads to increased insulation loss of life (LOL) and can also become a cause of dielectric failure [6]; and can be referred to as accelerated insulation aging. The risk of the DTR application can be approximated by the risk of having hot spots, obtained as the sum of the risks of accelerated insulation LOL and dielectric breakdown. The normal LOL of a transformer is defined as the daily LOL caused by a HST equal to the reference value $\theta_{0}$ [6]. Overloading the transformer can result in HSTs above $\theta_{0}$, which leads to additional LOL. The additional LOL is calculated as a percentage of normal LOL [2]. The transformer LOL in hours can be presented as a 
function of time and temperature (1) and follows an adaptation of the Arrhenius reaction rate theory [2].

$$
P L\left(\theta_{h s}\right)=100 \cdot t \cdot e^{\frac{B}{\theta_{0}+273}-\frac{B}{\theta_{h s}+273}} \quad[\text { hours }]
$$

where $\theta_{0}$ and $\theta_{h s}$ are the reference HST and the actual HST respectively in $\left[{ }^{\circ} \mathrm{C}\right], \mathrm{t}$ is the time in [hours], and $B=15000$ is the dimensionless aging rate constant [2].

The impact of LOL is defined by (2) [6].

$$
\operatorname{Im}_{L O L}\left(\theta_{h s}\right)= \begin{cases}\frac{\Delta t}{t_{0}} \cdot C_{t}, & \text { if } \theta_{h s} \geq \theta_{0} \\ 0, & \text { otherwise }\end{cases}
$$

where $t_{0}$ is the expected transformer remaining life as a percentage of total expected life, [\%]; $C_{t}$ is the cost of rewinding the transformer, in [SEK (Swedish krona)]; $\Delta t$ is the percentage of loss of life difference for the actual and reference temperatures, $\left[{ }^{\circ} \mathrm{C}\right]$ and can be defined by:

$$
\Delta t=\left(P L\left(\theta_{h s}\right)-P L\left(\theta_{0}\right)\right) / t_{n}
$$

where $t_{n}$ normal insulation life reference, [hours].

The probability of a dielectric failure during the time period $\left[t_{1}, t_{2}\right]$ can be estimated by (4) [6].

$$
\operatorname{Pr}\left(t_{1}<t<t_{2} \mid \theta\right)=H\left(t_{1} \mid \theta\right) \cdot\left(t_{2}-t_{1}\right)
$$

where $H\left(t_{1} \mid \theta\right)$ is the hazard function, given by [6]:

$$
H\left(t_{1} \mid \theta\right)=\frac{f\left(t_{1}\right)}{1-F\left(t_{1}\right)}
$$

in which $f(t)$ and $F(t)$ are the probability density function and the cumulative distribution function of the dielectric failure respectively.

The transformer degradation as a function of the temperature follows the Arrhenius reaction rate and the dielectric failure of a transformer can be described by a Weibull distribution [6] Therefore an Arrhenius-Weibull model presented by (6) and (7) can be used to describe the dielectric failure as a function of the temperature [6].

$$
\begin{aligned}
& f(t)=\frac{1}{\sigma t} e^{x-e^{x}} \\
& F(t)=1-e^{-e^{x}}
\end{aligned}
$$

where $\mathrm{x}$ is a stress as a function of time; $\sigma$ is the scale parameter for the Weibull distribution, $\sigma=1 / \beta$. $\beta$ is the shape parameter for the insulation material and is obtained by combining accelerated aging tests and the maximum likelihood method [7].

When a dielectric failure occurs, the transformer has to be replaced. Therefore. it is essential to calculate the impact of a dielectric failure by using (8) [6].

$$
\operatorname{Im}_{D F}\left(\theta_{h s}\right)= \begin{cases}C_{t}, & \text { if a failure occurs } \\ 0, & \text { otherwise }\end{cases}
$$

The risk associated with an event can be quantified using the product of the probability of the event and the consequences associated with it [8]. The risk associated with insulation LOL for a given load is defined by (9) [6].

$$
\begin{array}{r}
\operatorname{Risk}\left(\operatorname{Im}_{L O L} \mid \text { Load }\right)= \\
\int_{0}^{T} \int_{\theta_{0}}^{\theta_{h s}} \operatorname{Pr}\left(\theta_{h s} \mid L o a d\right) \cdot \operatorname{Im}_{L O L}\left(\theta_{h s}\right) d \theta d t[S E K]
\end{array}
$$

In a similar manner, the risk associated with dielectric failure for a given load is defined by [6]:

$$
\begin{array}{r}
\operatorname{Risk}\left(\operatorname{Im}_{D F} \mid \text { Load }\right)=\int_{0}^{T} \int_{\theta_{0}}^{\theta_{h s}} \operatorname{Pr}\left(\theta_{h s} \mid \text { Load }\right) . \\
\cdot H\left(t \mid \theta_{h s}\right) \cdot \Delta t \cdot \operatorname{Im}_{D F}\left(\theta_{h s}\right) d \theta d t[S E K]
\end{array}
$$

Thus, the total risk associated with the dynamic rating application is:

$$
\begin{array}{r}
\operatorname{Risk}_{D T R}= \\
\operatorname{Risk}\left(\operatorname{Im}_{L O L} \mid \text { Load }\right)+\operatorname{Risk}\left(\operatorname{Im}_{D F} \mid \text { Load }\right)[S E K]
\end{array}
$$

\section{B. Economic analysis}

There are two main benefits associated with dynamic asset rating: better utilization of existing equipments and possibility to increase system performance [9], which can become economically beneficial. The economic benefits of using DTR can be obtained using time discrete Net Present Value (NPV) calculations as in (12).

$$
N P V=\sum_{i=1}^{t} \frac{C_{i}}{(1+r)^{i}}-C_{0}
$$

where $C_{i}$ is the net cash inflow during a period $t ; C_{0}$ is the upfront investment cost; $\mathrm{i}$ is the time period, usually given in years; $\mathrm{r}$ is the discount rate per $i$.

Discount rate, $r$, is most commonly determined by the Weighted Average Cost of Capital (WACC) [10]. The distribution company is assumed to have a good credit rating, and the debt margin is assumed to be 1.7 which gives the cost of debt $3.96 \%$, equal to the European average [11]. The capital structure for WACC is assumed to be equal to the European average in the power sector, $50.66 \%$ equity and $49.34 \%$ debt and in this case $W A C C=6.93 \%$. The assumed wholesale price of electricity is 297.3 SEK/MW [12].

In our comparative NPV analysis we considered only marginal costs and revenue; costs associated with installation, land, and decommission are not being considered in the analysis.

Capital costs of the transformer are the upfront investment costs at year $=0$. The costs of a transformer and the DTR application for the 16 MVA transformer are costs that have the highest uncertainty level. NPV analysis aims to determine what should be the capital costs for the 16 MVA transformer with DR in order to match return on investment of the 19.4 MVA transformer.

Transformer losses represent energy that is lost due to the design of the transformer, and are divided into no-load losses and on-load losses. The cost of losses per year is defined as:

$$
\begin{array}{r}
\text { Cost }_{\text {losses }}=\left(\text { Losses }_{\text {no-load }}+\text { Losses }_{\text {on-load }}\right) . \\
h \cdot \text { Cost }_{\text {electricity }}[S E K]
\end{array}
$$


where $h$ is the number of hours in a year; Cost $_{\text {electricity }}$ is the whole-price for electricity [SEK/Wh]; Losses are in [W]. As the price of electricity is not time independent, a electricity forecast will be used to make assumptions of future trends. The electricity price in Europe has been increasing by an average of $3.2 \%$ each year since 2008 [13], the economic benefits of DTR are analyzed for 5 cases: $5 \%$ and $2 \%$, increase and decrease in the electricity price and no changes in the electricity price. The risk of the DTR application is quantified in currency units, and are included in the NPV calculation as expected costs. To simplify the analysis, the costs for operation and maintenance are assumed to be the same for both transformers.

\section{MODEL IMPLEMENTATION}

\section{A. Transformer Specification and Collected Data}

The transformer analyzed in this replacement is a 19.4 MVA transformer located in Sweden. The 16 MVA transformer is considered to have the same nominal characteristics, therefore the percentage of load and no-load losses is assumed to the same. The relevant information from the data sheet of the 19.4 MVA transformer as well as calculated values for a comparable 16 MVA transformer can be seen in Table I. The 16 MVA transformer was sized in [4], as the smallest size possible which respected the limits in the IEC limits for maximum contingency loading of current and HST.

TABLE I: Transformer's parameters [4]

\begin{tabular}{|ccc|}
\hline \multicolumn{3}{|c|}{ Transformer specification } \\
\hline Power (MVA) & 19.4 & 16 \\
Voltage (kV) & $44 / 22$ & $44 / 22$ \\
Load losses (W) & 137500 & 113402 \\
No load losses (W) & 7370 & 6078 \\
\hline
\end{tabular}

The data used for the 19.4 MVA transformer consists of one year of measurements of: load data; hottest-spot temperature; cost of new transformers. Corresponding data for $16 \mathrm{MVA}$ transformer was obtained using thermal models [3][4]. No future wind farm expansion is assumed to occur and thus the yearly load profile is assumed to remain unchanged.

\section{B. Risk Analysis}

From the HST distribution in Figure 1 it is seen that maximum HST for the 19.4 MVA transformer was $87.3^{\circ} \mathrm{C}$, whereas for the $16 \mathrm{MVA}$ transformer it does not exceed $120^{\circ} \mathrm{C}$. Therefore, using the one year of load data as a reference pattern for the transformer's lifetime operation, the risk will be zero for temperatures above $120^{\circ}$, given the zero probability of their occurrence. As seen in Figure 1, the probability of the 16 MVA transformer with DTR to exceed the reference value of $110^{\circ} \mathrm{C}$ is low $(0.21 \%)$. Lower probabilities of exceeding the reference temperature result in lower risks of accelerated insulation aging and dielectric failure.

In order to perform the risk analysis, the conditional probability distribution of HSTs given a certain load occurrence, $\operatorname{Pr}\left(\theta_{h s t} \mid L o a d\right)$ is calculated. The HST data is used to calculate the aging acceleration factor per measurement interval and the equivalent aging factor per hour. The information on aging of the transformer is used to calculate the percentage of normal insulation life lost per day, for each day the data was collected, as shown in Figure 2, where the vertical axis is scaled logarithmically.

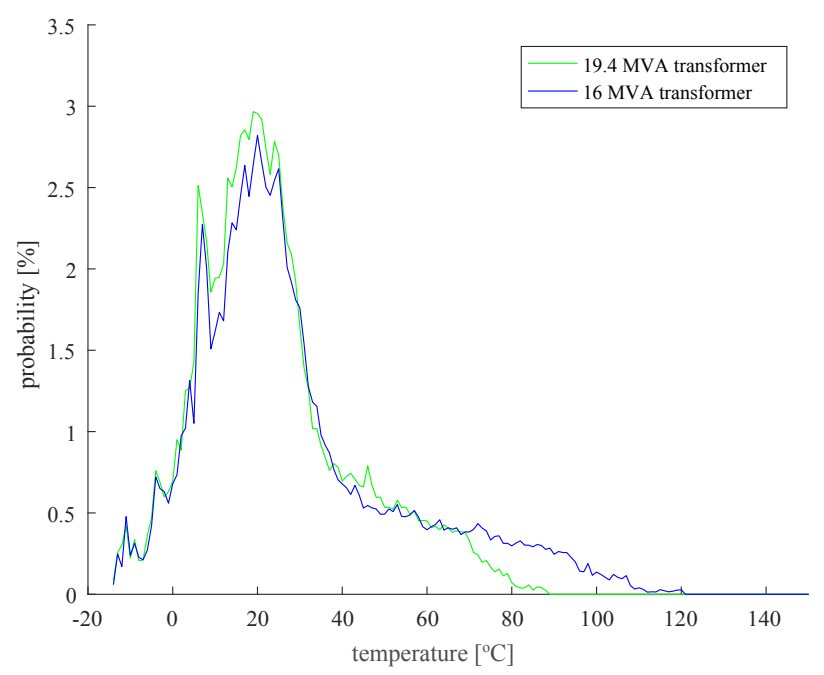

Fig. 1: Hottest-spot temperature probability distribution.

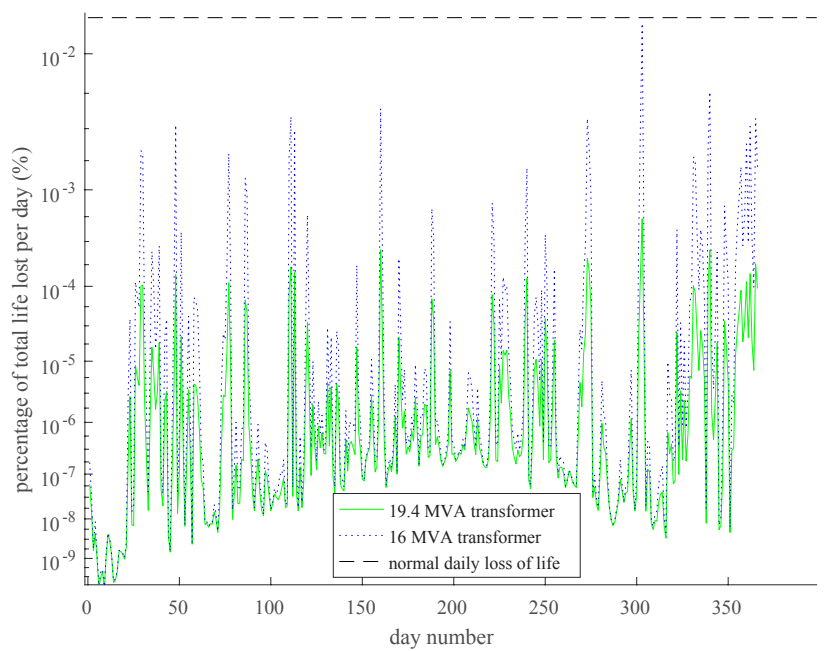

Fig. 2: Comparison of the percentage of total life lost per day, for one year of measurements.

The normal LOL is defined as the daily loss of life equal to that of a continuously loaded winding with hottest spot temperature of $\theta_{0}=110^{\circ} \mathrm{C}$ (for a $65^{\circ} \mathrm{C}$ rise transformer)[6]. From (1) and considering 17.12 years as the normal insulation life reference, $0.016 \%$ of life is lost per day.

From Figure 2, it can be seen that for the 16MVA transformer, the percentage of life lost per day is significantly higher than for the 19.4 MVA transformer. Nevertheless, these values remain significantly lower than the normal daily loss of life. This implies an insulation life higher than the normal reference life of 17.12 years.

In Table II, the total life lost within a year is compared to the normal loss of life. For the 19.4 MVA transformer, in the measured year, only $0.08 \%$ ( 7.24 hours) of the normal yearly 
loss of life occurs, whereas for the 16 MVA transformer with DTR, this value increases to $1.55 \%$ (135.9 hours).

TABLE II: Loss of insulation-life analysis

\begin{tabular}{|l|c|c|}
\hline Analyzed Scenario & $\begin{array}{c}\text { Loss of life per } \\
\text { year [hours] }\end{array}$ & $\begin{array}{c}\text { Expected total insulation } \\
\text { life [years] }\end{array}$ \\
\hline Reference value & 8760.0 & 17.12 \\
\hline 16 MVA Transformer & 135.9 & 1103 \\
\hline 19.4 MVA Transformer & 7.2 & 20709 \\
\hline
\end{tabular}

A percentage of LOL for each interval for each HST value is obtained from the normal percentage of LOL per day $(0.016 \%)$, in order to obtain $\Delta t$, as defined in (3). The impact of accelerated LOL is obtained for different HST values for every 5 minutes of load measurement interval. The expected remaining life, $t_{0}$, relates the impact of the accelerated LOL to the age of the insulation at the time of the HST increase. $t_{0}=1103$ [years] is given as a percentage of the expected transformer life, from Table II. Figure 3 shows the impact that a certain HST lasting for 5 minutes will have during different years of operation with its maximum at year 1103 .

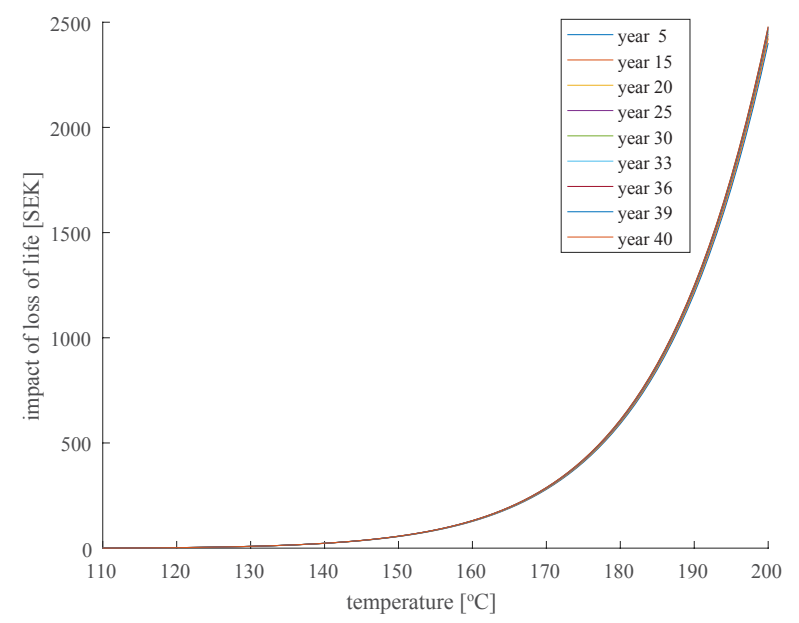

Fig. 3: Impact of life lost during $5 \mathrm{~min}$ for each year of operation

The risk of accelerated loss of life, per load, for 5 minutes of continuous loading in different operation years, was calculated using (9) and can be found in Figure 4.

To determine frequency of transformer loading, the risk of increased LOL for each operation year is calculated using the impact per load level and the frequency function of each load level. Figure 5 shows the risk of increased LOL throughout the expected lifetime of the 16 MVA transformer with DTR. The risk of dielectric failure increases for temperatures above $140{ }^{\circ} \mathrm{C}$. Since the maximum HST for the 16 MVA transformer is $119.8^{\circ} \mathrm{C}$, the risk of dielectric failure is not taken into account. The total risk of the DTR application will be equal to the risk of accelerated loss of life.

\section{Economic Analysis}

The NPV of no-load and on-load losses for both transformers, assuming stagnant electricity price over the course of 1103 years are shown in Figure 6 and Figure 7 respectively.

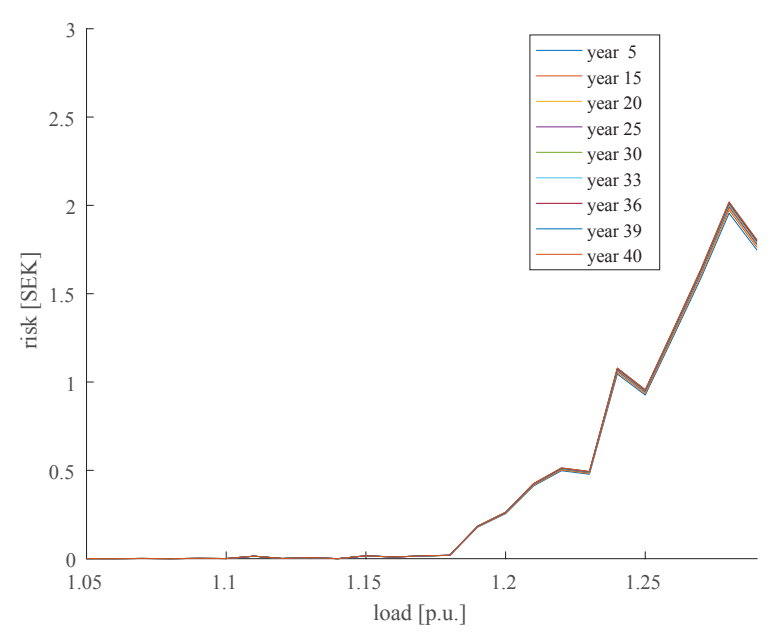

Fig. 4: Risk of accelerated loss of life during $5 \mathrm{~min}$ for different operation years (Year 0 bottom curve, year 40 top curve)

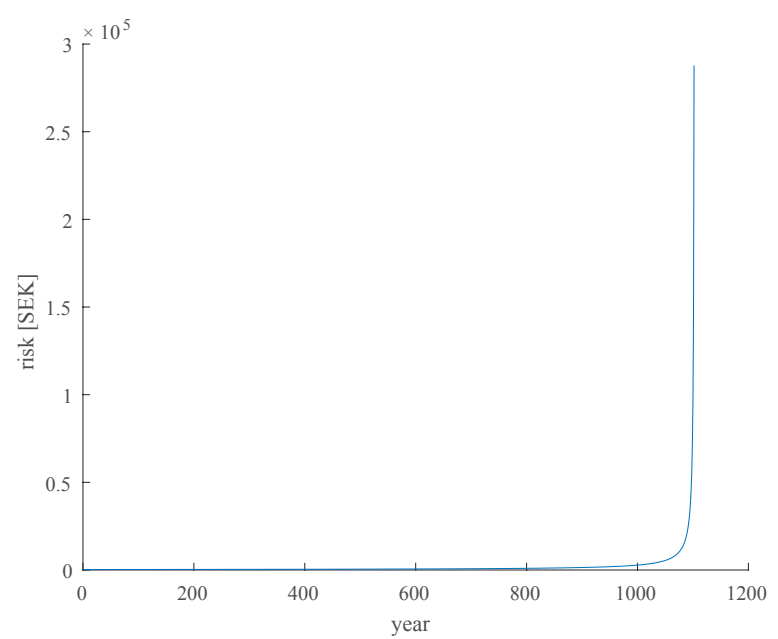

Fig. 5: Risk of accelerated loss of life per operation year using a 16MVA transformer in the given application

The additional cost of no-load and on-load losses for 19.4 MVA transformer compared to the 16 MVA transformer are shown in Figure 8 and Figure 9 respectively.

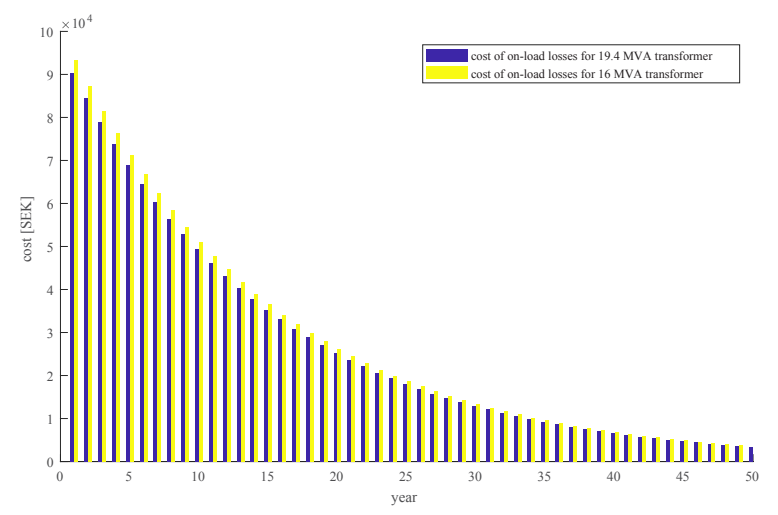

Fig. 6: NPV of no-load losses for 19.4 and 16 MVA transformers assuming stagnant electricity price 


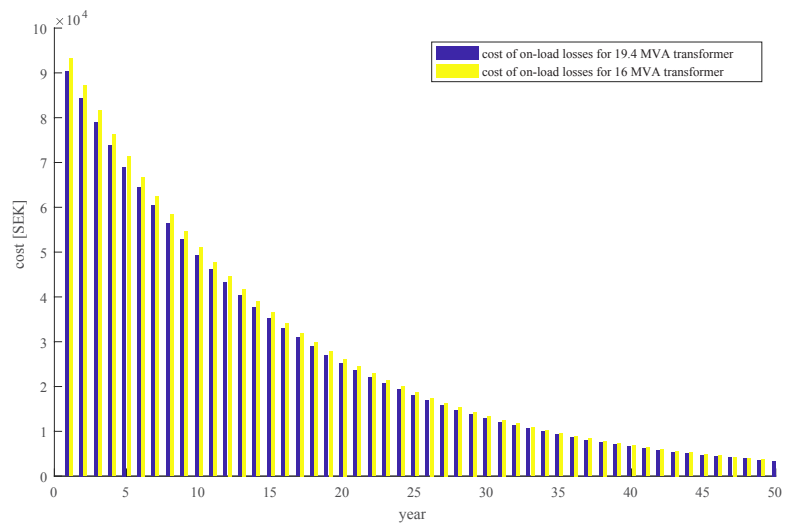

Fig. 7: NPV of on-load losses for 19.4 and 16 MVA transformers assuming stagnant electricity price

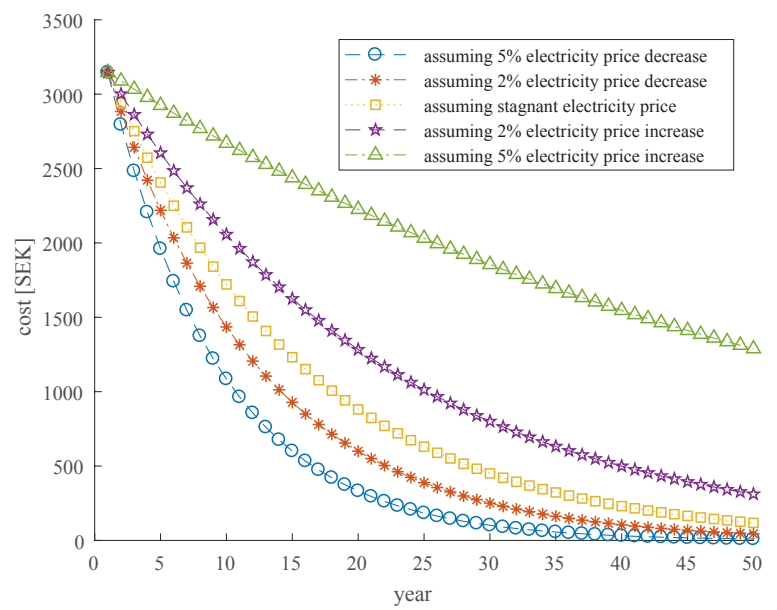

Fig. 8: NPV of the additional cost of no load losses for 19.4 MVA transformer compared to the 16 MVA transformer

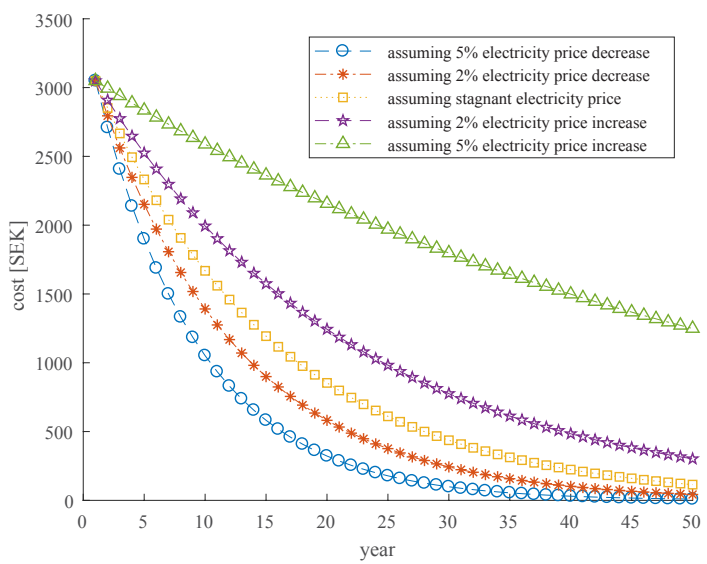

Fig. 9: NPV of the additional cost of on load losses for 16 MVA transformer compared to the 19.4 MVA transformer

A load frequency distribution of the 16 MVA transformer is obtained by scaling the current value of the 19.4 MVA transformer; the distributions are shown in Figure 10.

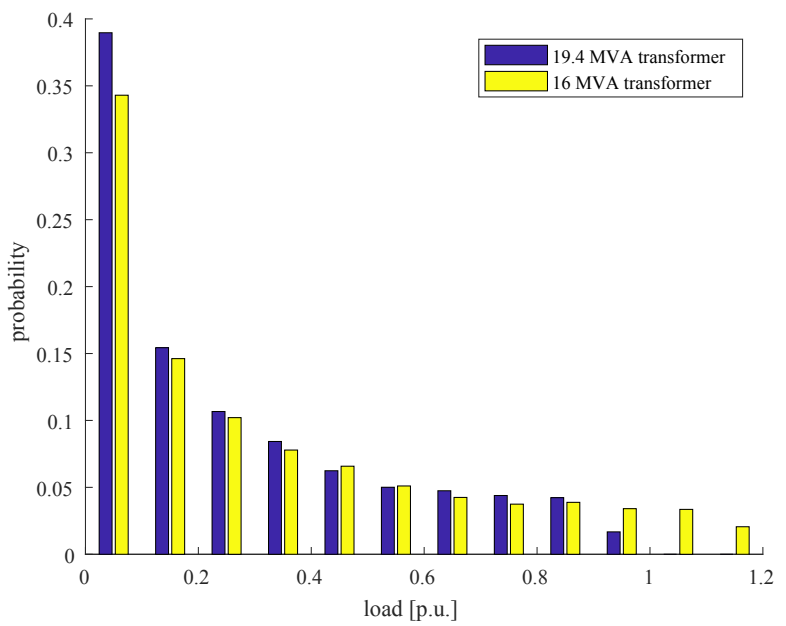

Fig. 10: Load frequency distribution for the transformers [4]

The NPV of cost of risk for the 16 MVA transformer is shown in Figure 11.

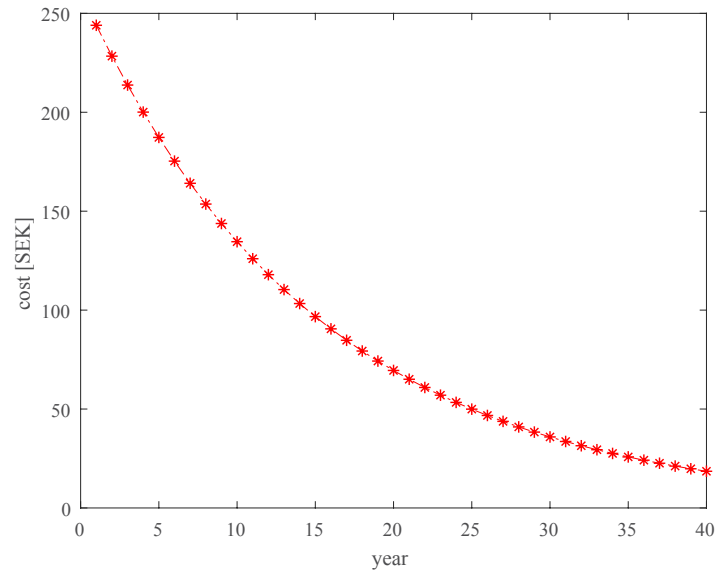

Fig. 11: NPV of the cost of risk for the 16 MVA transformer

Table III shows the minimum required difference between the capital costs of transformers in order to obtain the same return on investment.

TABLE III: Necessary difference in capital cost for the 16 MVA transformer to have the same return of investment

\begin{tabular}{|l|c|}
\hline Electricity price forecast & Difference in capital cost (kSEK) \\
\hline $5 \%$ decrease & 2949 \\
\hline $2 \%$ decrease & 2658 \\
\hline Stagnant & 2324 \\
\hline $2 \%$ increase & 1719 \\
\hline $5 \%$ increase & -1540 \\
\hline
\end{tabular}

The risk and economical analysis show that 16 MVA transformer has a potential to have significantly impact on economy.

IV. Methodology for TRAnsformer SpecificAtion

Conventional transformer design methodologies are an optimization problem to minimize the manufacturing costs [14] 
with the desired MVA rating, total line losses and equivalent reactance as constraints [15]. Based on the performed risk and economic analysis we propose a step by step guideline for dimensioning a transformer with DR at specification stage; main steps are presented as a flowchart, shown in Figure 12.

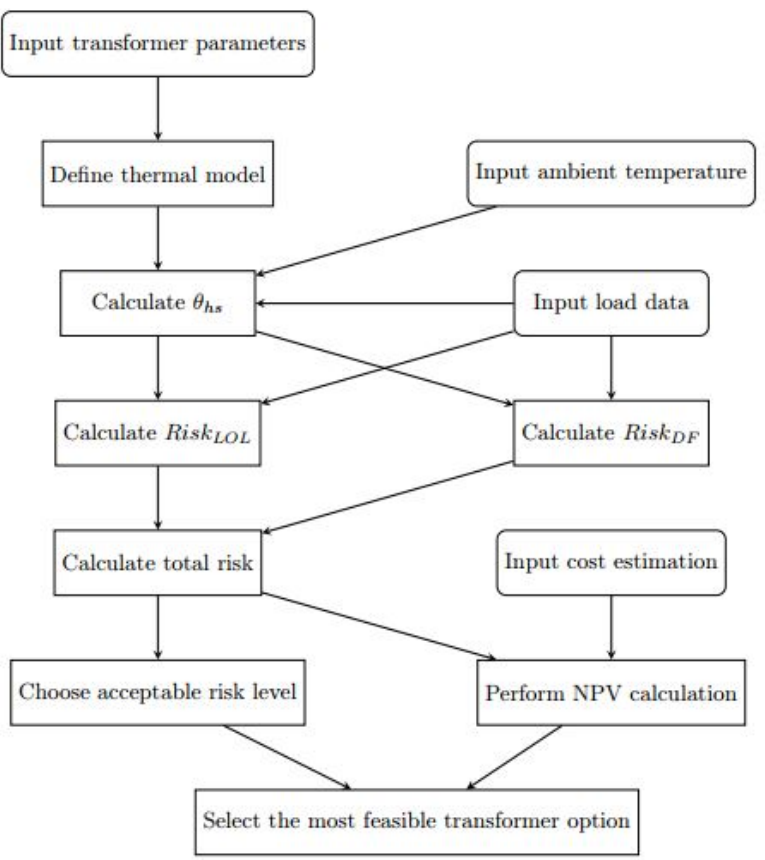

Fig. 12: Flowchart of transformer selection methodology

The important part of the following algorithm is risk of LOL calculation. The cumulative risk over one year is obtained by

$$
\operatorname{Risk}\left(\operatorname{Im}_{1}\right)=\sum_{i=1}^{n} \operatorname{Risk}\left(\operatorname{Im}_{1} \mid \operatorname{Load}_{i}\right) \omega_{i}
$$

where $\omega_{i}=\frac{\Delta t_{i}}{t_{\text {total }}}$ is the weight; $\Delta t_{i}$ is the total time during which the load is equal to $\operatorname{Load}_{i}$.

Increased temperature in the transformer winding results in increased probability of dielectric failure. In case of a dielectric failure, the transformer has to be replaced. The cumulative yearly risk of dielectric failure, $\operatorname{Risk}\left(\operatorname{Im}_{2}\right)$, is given analogously to the risk of LOL. The risk of LOL and risk of dielectric failure are input parameters for the total risk calculation as in (15).

$$
\operatorname{Risk}_{D T R}=\operatorname{Risk}\left(\operatorname{Im}_{1}\right)+\operatorname{Risk}\left(\operatorname{Im}_{2}\right)
$$

The choice of the transformer is based on the level of risk that the customer decides on. However, the transformer has to be dimensioned in a way that the hottest spot temperature does not exceed the limit of $200^{\circ} \mathrm{C}$ [2].

\section{CONCLUSION}

A quantitative risk analysis of the accelerated insulation aging was performed for the DTR application. Due to the HSTs remaining predominantly below the reference value of $110^{\circ} \mathrm{C}$, the yearly $\mathrm{LOL}$ remained below the normal LOL level for both scenarios. The calculated difference in capital cost for 19.4 MVA and 16 MVA transformers indicates high profitability of implementing DTR for the analyzed case.

The risk and economic analysis indicate a profitable scenario at an acceptable risk. Based on the risk and economic analysis' results, the 19.4 MVA transformer can be replaced by a dynamically rated 16 MVA transformer without a significant increase in risk and without exceeding the limits of contingency loading and winding temperature stated in [2].

Nowadays, DTR is not well popularized technology, partially due to lack of information about the application during specification stage. A methodology for the risk and economic analysis of DTR applications and can be used as specification guidance for dynamically rated transformer.

\section{ACKNOWLEDGMENT}

The authors would like to thank Energiforsk AB, Wind research program for financing the project.

\section{REFERENCES}

[1] W. Li, Risk assessment of power systems : models, methods, and applications. IEEE Press Series on Power Engineering, 2 ed., 2014.

[2] IEEE Std C57.91-1995: IEEE Guide for Loading Mineral-Oil-Immersed Transformers. IEEE, 1996.

[3] D. Susa and H. Nordman, "Iec 60076-7 loading guide thermal model constants estimation," International Transactions on Electrical Energy Systems, vol. 23, pp. 946-960, Oct 2013.

[4] T. Zarei, "Reliability analysis of dynamically rated transformer," diploma thesis, Electrical Engineering School, KTH Royal Institute of Technology, Stockholm, May 2017.

[5] J. Roselind, F. Edström, P. Hilber, and L. Söder, "On optimal transformer capacity rating," Elsevier, 2013.

[6] W. Fu, J. Mccalley, and V. Vittal, "Risk assessment for transformer loading," Power Systems, IEEE Transactions on, vol. 16, pp. 346-353, August 2001.

[7] R. Madavan and S. Balaraman, "Failure analysis of transformer liquidsolid insulation system under selective environmental conditions using weibull statistics method," Engineering Failure Analysis, vol. 65, pp. 2638, Jul 2016.

[8] M. Rausand, Risk assessment theory, methods, and applications. Statistics in practice, Hoboken, N.J.: Wiley, 2011.

[9] C. J. Wallnerstrom, P. Hilber, P. Soderstrom, R. Saers, and O. Hansson, "Potential of dynamic rating in sweden," pp. 1-6, IEEE, Jul 2014.

[10] I. Pricing and R. Tribunal", "Weighted average cost of capital: Incorporating a return capital in the 2013 electricity determination." Available at https://www.ipart.nsw.gov.au/files/sharedassets/website/ trimholdingbay/draft_methodology_paper_-_weighted_average_cost_ of capital - november_2012.pdf. [Online; accessed 1-Oct-2017].

[11] A. Damodaran, "Cost of capital by industry sector." Available at http: //pages.stern.nyu.edu/ adamodar/New_Home_Page/datacurrent.html, 2017. [Online; accessed 02-Oct-2017].

[12] "Nordpool", "Day ahead prices of electricity." Available at http://www.nordpoolspot.com/Market-datal/Dayahead/Area-Prices/ SE/Hourly1/?view=table. [Online; accessed 24-Oct-2017].

[13] "Report from the commission to the european parliament, the council, the european economic and social committee and the committee of the regions," European Commission. [Online; accessed 08-Nov-2017].

[14] E. I. Amoiralis, P. S. Georgilakis, and E. Litsos, "Methodology for the optimum design of power transformers using minimum number of input parameters," 2006.

[15] A. A. Adly and S. K. Abd-El-Hafiz, "A performance-oriented power transformer design methodology using multi-objective evolutionary optimization," Journal of Advanced Research, vol. 6, pp. 417-423, May 2015 . 